\title{
An Efficient Directly Conversion of the Ethyl $p$-Methoxycinnamate into $N, N$-dimethyl- $p$-Methoxycinnamamide and study the structure-activity relationship on anti-inflammatory activity
}

\author{
Ismiarni Komala1 ${ }^{*}$, Supandi1, Ahmad Thantowi1, Andrianopsyah Mas Jaya Putra²
}

1. Department of Pharmacy, Faculty of Health Sciences, Universitas Islam Negeri Syarif Hidayatullah Jakarta.Jl. Kertamukti No 5, Pisangan Ciputat, Indonesia

2. Pusat Penelitian Kimia-LIPI, Gedung 452-Kawasan Puspitek, Tangerang Selatan 15314

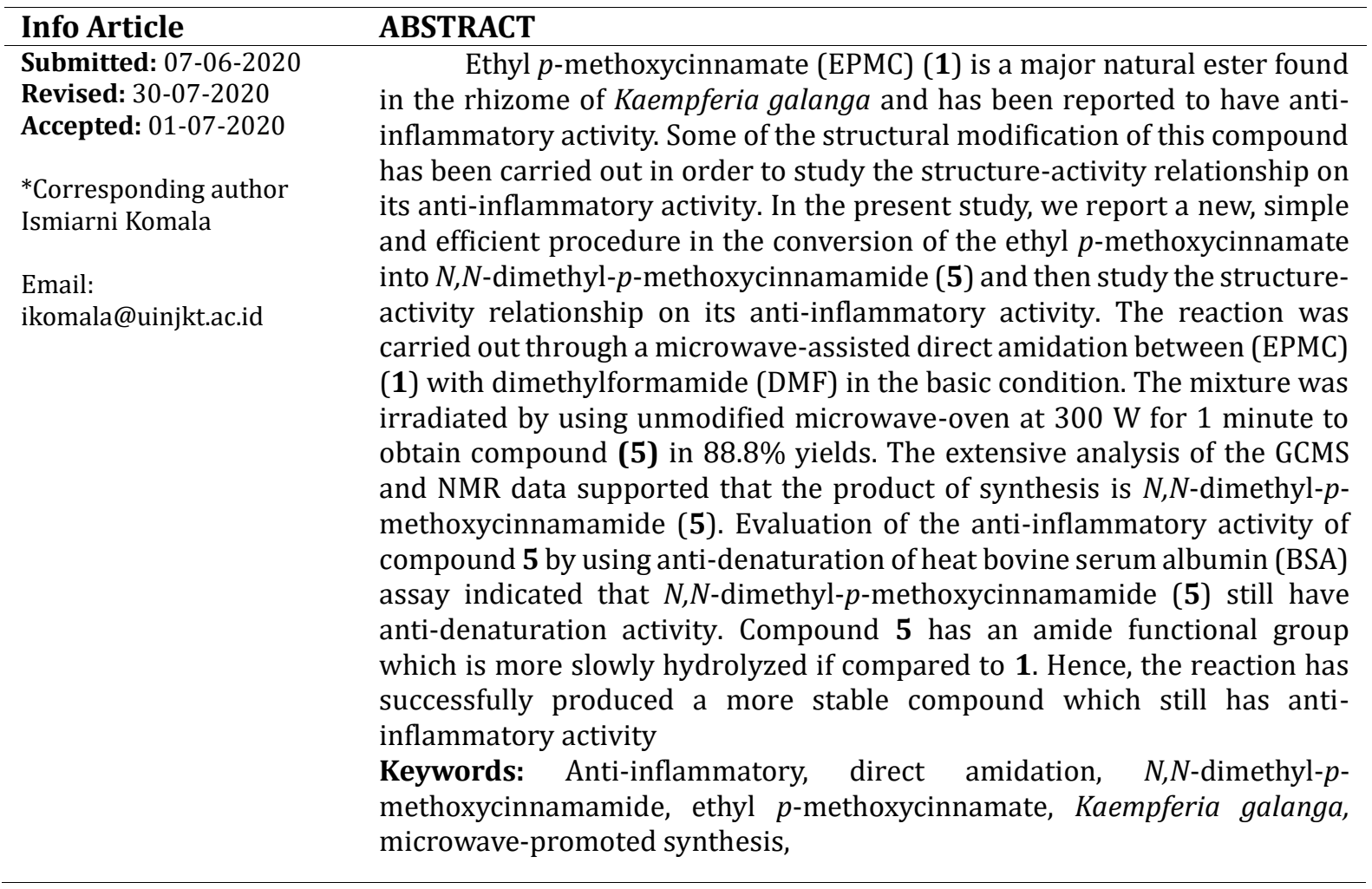

\section{INTRODUCTION}

Ethyl $p$-methoxycinnamate (EPMC) (1) is an ester anti-inflammatory compound that is easily isolated from the rhizome of Kaempferia galanga (Komala, et al., 2018; Komala et al., 2017). Our previous research suggested that ethyl ester of the EPMC (1) is responsible for its anti-inflammatory properties. Conversion of EPMC (1) into other ester cause decreasing anti-inflammatory activity (Komala et al., 2018). In the other investigation, we have also successfully converted EPMC (1) into cinnamamide derivatives, $N$-(2-hydroxyethyl)- $p$ methoxycinnamamide (2), $\quad N, N$-bis-(2hydroxyethyl)- $p$-smethoxycinnamamide (3) and $p$ methoxycinnammamide (4) in which these compounds showed higher anti-inflammatory activity than 1 (Figure 1) (Komala et al., 2017).
Cinnamamides are compounds that have an amide bond and have been reported to have various pharmaceutical activities. In the simple method, the amide bond was prepared through direct condensation of carboxylic acids and amines. However, this reaction does not occur spontaneously at ambient temperature. In order to circumvent carboxylate-ammonium salts formation in this reaction, the reaction needs to be conducted at very harsh conditions $\left(>100^{\circ} \mathrm{C}\right)$. Therefore, it is necessary to initiate the activate carboxylic acids by using coupling reagent prior to treatment with amines (Figueiredo, et al., 2016; Pattabiraman and Bode, 2011). In recent research, it has been developed the catalytic protocol in performing direct amidation of carboxylic acids with amines, in which boronic acid 
derivatives are found as a prominent catalyst used (Pattabiraman and Bode, 2011; Sabatini, et al., 2017). Another method that is currently being considered in order to form amide bonds is a direct amidation of the ester by using a variation of amines. The aminolysis of the ester by using amines becomes an attraction in the organic synthesis due to its simplicity, economical, and large availability of the starting material (Vrijdag et al., 2014).

In continuing our concern on the study structure-activity relationship of the cinnamamide derivative of the EPMC (1), here we are reporting a new, simple and efficient procedure for the synthesis of $N, N$-dimethyl- $p$-methoxycinnamamide (5) and then study its structure-activity relationship. The reaction was conducted through a microwave-promoted direct amidation of EPMC (1) and DMF in the presence of $\mathrm{NaOH}$ (Figure 1). The product of the reaction was evaluated for its antiinflammatory activity and then further analyzed for its structure-activity relationship on the antiinflammatory activity.

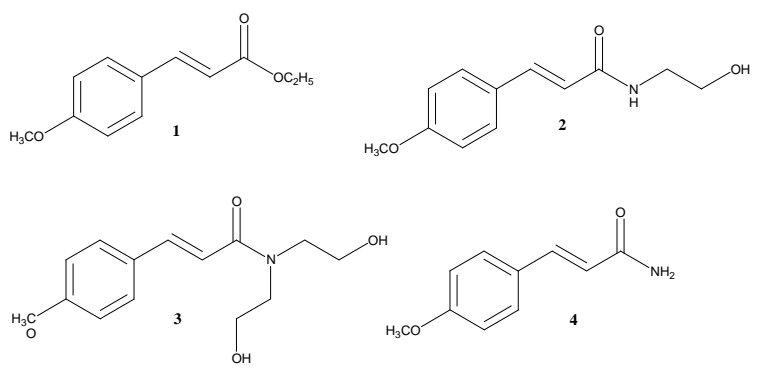

Figure 1. Ethyl p-methoxycinnamate (1) and its cinnamamide derivatives

\section{MATERIAL AND METHODS General}

The melting point of the synthesized product was measured by using the melting point apparatus Stuart SMP10 without correction. The ${ }^{1} \mathrm{H}-\mathrm{NMR}$ was measured on Jeol-500 $\mathrm{MHz}\left({ }^{1} \mathrm{H} ; 500 \mathrm{MHz}\right)$ instruments. The reaction was carried out using a microwave oven assisted (Samsung). Product of reaction was analyzed by using GCMS: GC/MS-MSD 7890A/5975C (Agilent Technologies) with the condition was in accordance with our previous reported (Komala, et al., 2018; Komala et al., 2017).

\section{Chemicals}

Methanol (Merck), DMF (Merck), ethanol (Merck), Na diclofenac (Sigma-Aldrich), HCl (smart lab), Bovine serum albumin fraction V (SigmaAldrich), $\mathrm{NaOH}$ (Merck), Trizma Base (SigmaAldrich), NaCl (Merck), TLC plate 60 F254 (Merck).

\section{Plant material}

The rhizome of $K$. galanga was collected from BALITRO (Balai Penelitian Obat dan Rempah) Bogor, West Java, Indonesia in May 2015. This specimen was identified in Herbarium Bogoriense, Research Center for Biology, Indonesian Institute of Sciences, Bogor, Indonesia.

\section{Extraction and Isolation of EPMC (1)}

Extraction and isolation of EPMC (1) were conducted in accordance with our previously reported (Komala et al., 2017).

\section{Conversion of EPMC (1) into $N, N$-dimethyl $p$ - methoxycinnamamide (5).}

In a test tube with the cup, 206mg (1mmol) of EPMC (1) was added into the mixture of $10 \mathrm{mmol} \mathrm{NaOH}$ in $2 \mathrm{~mL}$ ethanol and $2 \mathrm{~mL}$ of dimethylformamide (DMF). The mixture was then irradiated by using an unmodified microwave oven at $300 \mathrm{~W}$ for 1 minute. The product of the reaction was extracted by using ethyl acetate and $\mathrm{H}_{2} \mathrm{O}(1: 1)$, and then the ethyl acetate fraction was collected and evaporated to give $182.5 \mathrm{mg}$ of white amorphous of $N, N$-dimethyl- $p$ methoxycinnamamide (5) (yield 88.6\%). mp:132$135^{\circ} \mathrm{C}$. GCMS : 205 [M] $^{+}, 161$ (base peak), 133, 118, 103, 89, 77, 63, 44. ${ }^{1} \mathrm{H}-\mathrm{NMR}$ : 3.05 (s, 3H), 3.16 (s, $3 \mathrm{H}), 3.83(\mathrm{~s}, 3 \mathrm{H}), 6.77(\mathrm{~d}, 1 \mathrm{H}, \mathrm{J}=15 \mathrm{~Hz}), 7.64(\mathrm{~d}, 1 \mathrm{H}, \mathrm{J}$ $=15 \mathrm{~Hz}), 6.90(\mathrm{~d}, 2 \mathrm{H}, \mathrm{J}=9.1 \mathrm{~Hz}), 7.48(\mathrm{~d}, 2 \mathrm{H}, \mathrm{J}=8.5$ $\mathrm{Hz}){ }^{1} \mathrm{H}-\mathrm{NMR}$ data is in accordance to that of the previously reported (Pathan and Patil, 2008).

\section{Anti-Denaturation of Heat BSA Assay}

Anti-inflammatory activity was evaluated by using anti denaturation of Heat BSA Assay. The sample was dissolved in methanol at various concentrations and then measured its anti denaturation activity in the procedure is in accordance with our previously reported (Komala, et al., 2018).

\section{RESULTS AND DISCUSSION}

In this research, we synthesized the $N, N$-dimethyl- $p$-methoxycinnamate (5) through the direct amidation of EPMC (1) by using $\mathrm{DMF}$ in the presence of $\mathrm{NaOH}$ (dissolved in ethanol). In order to find an optimal condition of reaction, initially, EPMC (1 mmol) and DMF $(2 \mathrm{~mL})$ were reacted in a variety amount of $\mathrm{NaOH}$ in $2 \mathrm{~mL}$ ethanol. The reaction was conducted by using an unmodified microwave oven at $300 \mathrm{~W}$ for $1 \mathrm{~min}$ and the result of the reaction was monitored by using TLC (Table I). 
Table I. Optimization of the amount of $\mathrm{NaOH}$ for the synthesis of $N, N$-dimethyl- $p$-methoxycinnamamide (5)

\begin{tabular}{cccccc}
\hline Entry & EPMC $(1)(\mathrm{mol})$ & DMF $(\mathrm{mL})$ & Ethanol $(\mathrm{mL})$ & $\mathrm{NaOH}(\mathrm{mmol})$ & Result \\
\hline 1 & 1 & 2 & 2 & 1 & - \\
2 & 1 & 2 & 2 & 5 & - \\
3 & 1 & 2 & 2 & 10 & + \\
\hline
\end{tabular}

Note: (-): did not give a product of synthesis, $(+)$ : successfully gave the product of synthesis

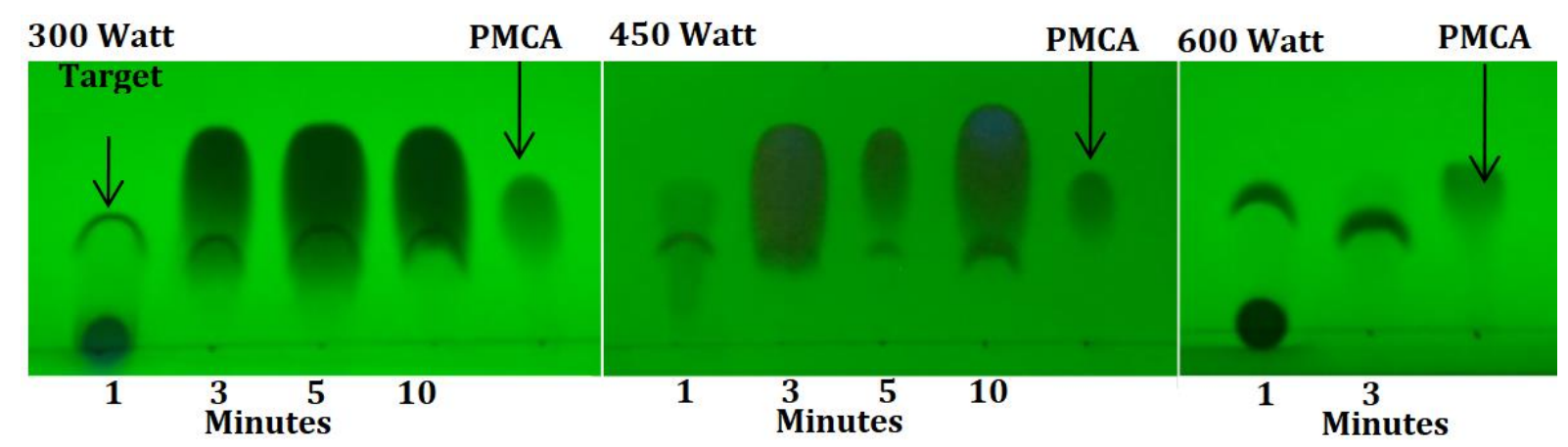

Figure 2. TLC monitoring of the reactions at 300, 450 and 600 Watt in a variation of times (eluent n-hexaneEtOAc 3:2)

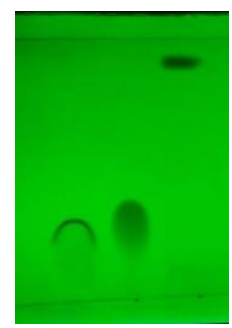

123

Figure 3. TLC monitoring of Product of reaction (eluent n-hexane-EtOAc 3:2). 1: Amide product (5), 2: Hydrolysis product (6), 3: EPMC (1)

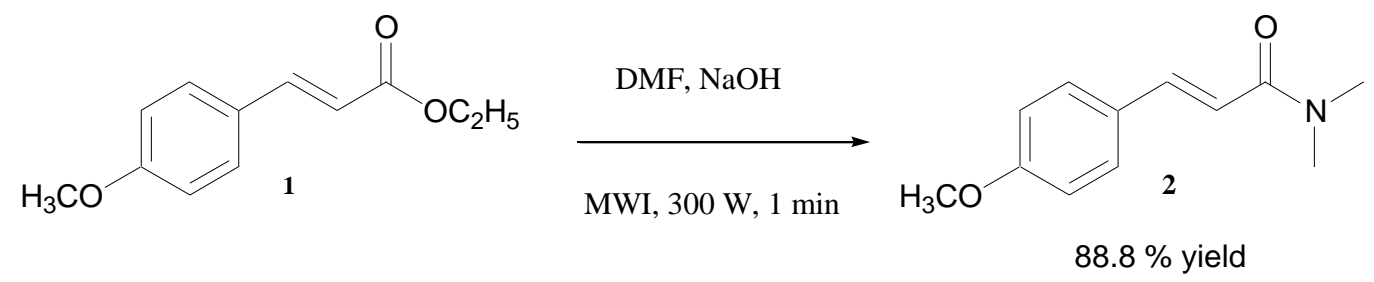

Figure 4. Direct amidation of EPMC (1) to synthesize $N, N$-dimethyl- $p$-methoxycinnamamide (5)

Unfortunately, there was no indication of product formation in the presence of 1 and $5 \mathrm{mmol} \mathrm{NaOH}$ in $2 \mathrm{~mL}$ ethanol. Eventually, the product of synthesis was successfully formed in the presence of $10 \mathrm{mmol}$ $\mathrm{NaOH}$ in 2 mLethanol.

The next optimization was conducted in order to find the optimum power of microwaveoven and time of reaction for the synthesis. The mixture containing $\mathrm{NaOH}(10 \mathrm{mmol})$ in ethanol
(2mL) and DMF (2mL) was then added EPMC (1mmol), subsequently, the mixture was irradiated by using the variations in power microwave-oven and reaction times. The result of the reaction was monitored by using TLC and compared to the product of hydrolysis of EPMC, $p$-methoxycinnamic acid (PMCA) (6). The reaction which was carried out by using microwave-oven at 300 Watt in $1 \mathrm{~min}$ gave a better result compared to the other 


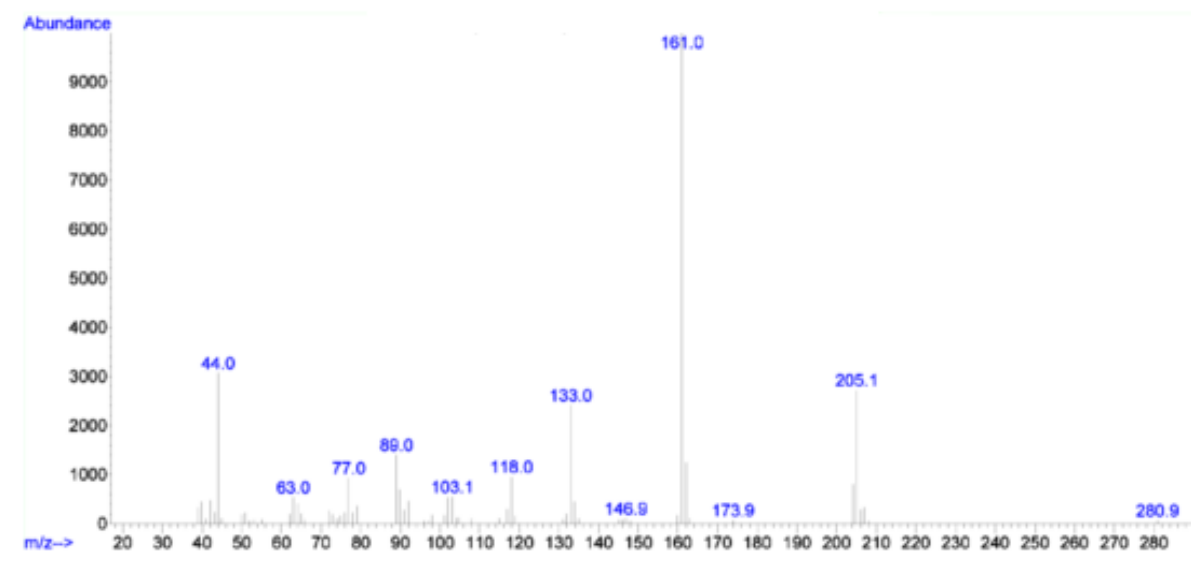

Figure 5. MS data of $N, N$-dimethyl- $p$-methoxycinnamamide (5)

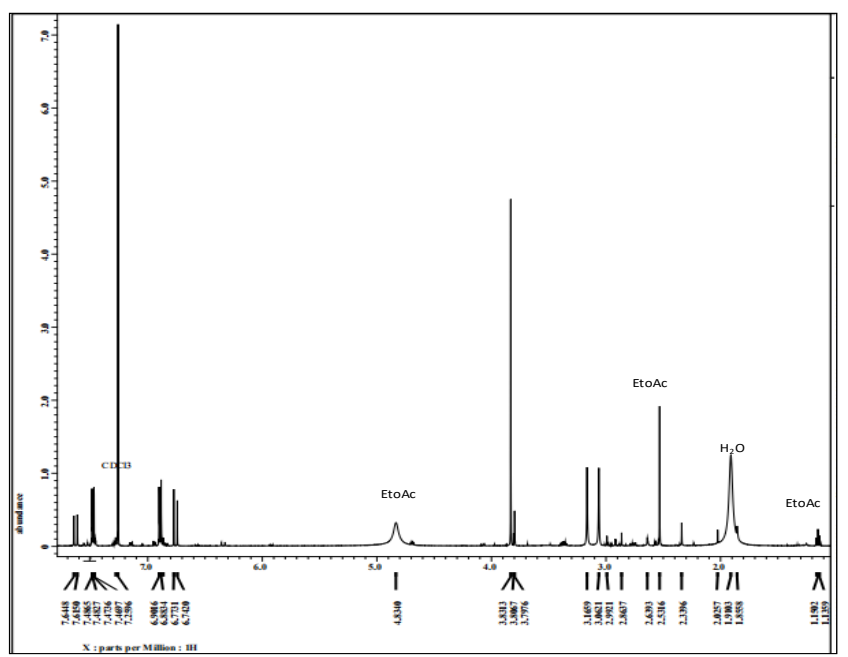

Figure 6. The NMR spectrum of 5

conditions (Figure 2). The fact in this optimization showed that the longer time used for the reaction, the more product of PCMA (6) was formed. It also found that the increasing power of microwave used causes increasing PCMA (6) formed. A comparison of the amide product (5), PCMA (6) and EPMC (1) (Figure 3 and 4).

Successful conversion of the EPMC (1) to form $N, N$-dimethyl- $p$-methoxycinnamamide (5) was occurred through a substitution acyl nucleophilic reaction of EPMC (1) with dimethylamine, in which dimethylamine is formed as product degradation of DMF in the solution of $\mathrm{NaOH}$ (Buncel and Symons, 1970). The product of the reaction was successfully formed when the reaction was carried out in the mild condition (300W, 1 min) and turns to produce a hydrolysis product ( $p$-methoxycinnamic acid when the high- power of microwave-oven and a long time of reaction was used more than $300 \mathrm{~W}, 1 \mathrm{~min}$. In our prediction, under mild conditions, dimethylamine was rapidly formed and then directly reacted with EPMC. On the other hand, the reaction produced a hydrolysis product when the power of microwaveoven and time of reaction was increased.

Compound 5 was obtained as a white amorphous with the melting point of $132-135^{\circ} \mathrm{C}$. Analysis of the MS data of GCMS indicated the presence of a molecular ion peak [M] ${ }^{+}$at $205 \mathrm{~m} / \mathrm{z}$, which is correlated to the molecular formula of $\mathrm{C}_{12} \mathrm{H}_{15} \mathrm{NO}_{2}$. The base peak is found at $\mathrm{m} / \mathrm{z} 161$, which is typical of the presence of a $p$ methoxycinnamate moiety (Komala, Supandi, \& Hardiansyah, 2018). This peak occurs due to the loss of the $-\mathrm{N}\left(\mathrm{CH}_{3}\right)_{2}$ from the whole structure of compound 5 (Figure 5). 
The ${ }^{1} \mathrm{H}-\mathrm{NMR}$ spectrum (Figure 6) indicated the presence of trans-configuration of the $p$ methoxycinnamate moiety which is suggested by the presence of $\delta .77(\mathrm{~d}, 1 \mathrm{H}, \mathrm{J}=15 \mathrm{~Hz}), 7.64(\mathrm{~d}, 1 \mathrm{H}, \mathrm{J}=$ $15 \mathrm{~Hz}), 6.90(\mathrm{~d}, 2 \mathrm{H}, \mathrm{J}=9.1 \mathrm{~Hz}), 7.48(\mathrm{~d}, 2 \mathrm{H}, \mathrm{J}=8.5$ $\mathrm{Hz}), 3.83(\mathrm{~s}, 3 \mathrm{H})$. The pattern of these signals was in accordance with our previous reported (Komala, et al., 2018). The rest signals at $\delta 3.05(\mathrm{~s}, 3 \mathrm{H}), 3.16$ (s, $3 \mathrm{H})$ were indicated the presence of $-\mathrm{N}\left(\mathrm{CH}_{3}\right)_{2}$. Hence it suggested that this compound is $N, N$ dimethyl- $p$-methoxycinnamamide (5). ${ }^{1} \mathrm{H}$-NMR data is in accordance with that of the previously reported which was confirmed that compound 5 is $N, N$-dimethyl- $p$-methoxycinnamamide (Pathan \& Patil, 2008).

BSA anti-denaturation assay indicated that compound $\mathbf{5}$ has anti-inflammatory activity (Figure 7). Williams et al have suggested that any compounds that have inhibition denaturation value greater than $20 \%$ were considered as having antiinflammatory properties and have the potency to be developed as anti-inflammatory drugs (Williams et al., 2008). Over range concentration of compound $\mathbf{5}$ at $6.25,12.5,25$ and $50 \mathrm{ppm}$, concentration at $25 \mathrm{ppm}$ was found as the minimum concentration that still inhibits denaturation of BSA greater than $20 \%$ (the percentage of inhibition is $23.4 \%$ ), meanwhile the higher inhibiting denaturation was shown by concentration of $50 \mathrm{ppm}$ (percentage of inhibition is $34.6 \%$ ). In our previous reported, cinnamamides that were synthesized from EPMC (1), $N-(2-$ hydroxyethyl)-p-methoxycinnamamide (2) and $N, N$-bis-(2-hydroxyethyl)- $p$-methoxycinnamamide (3) showed higher anti-inflammatory activity than EPMC (1).

However, in this investigation, compound $\mathbf{5}$ showed lower anti-inflammatory activity compared to EPMC (1), in which compound 1 still have inhibition of denaturation activity at a concentration of 0.1 (percentage of inhibition is $32.9 \%$ ). Compounds $\mathbf{2}$ and $\mathbf{3}$ are cinnamamides that have $N$-ethyl hydroxy substituent. Both compounds showed higher anti-inflammatory activity compared to EPMC (1). Compound $\mathbf{4}$ is a cinnammamide that does not have substituent attached to its Nitrogen atom, and antiinflammatory activity tends to decrease if compared to EPMC (1) (Komala, et al., 2018; Komala et al., 2017). When the EPMC (1) was converted to a cinnamamide that has dimethyl substituent at the nitrogen atom, the antiinflammatory of this derivative is lower compared to EPMC (1). Hence, it suggested that the more hydrophilic substituent attaches to the nitrogen atom of cinnamamide derivatives cause increasing its anti-inflammatory activity. Meanwhile, the presence of the lipophilic substituents such as $\mathrm{N}, \mathrm{N}$ dimethyl causes a decrease in anti-inflammatory activity. As already known, drugs that contain ester group tend to susceptible to be hydrolyzed, therefore in the further pharmaceutically development of this drug, we must concern about its stability. Even though a drug that has amide drugs are also susceptible to hydrolysis, but these compounds have a lower rate if compare to the ester drugs (Waterman et al., 2002). Hence, in the view of the stability, compound $\mathbf{5}$ is more stable than 1. Hence, the conversion of the EPMC (1) into $N, N$-dimethyl- $p$-methoxycinnamamide (5) has produced more stable derivatives that still have anti-inflammatory activity.

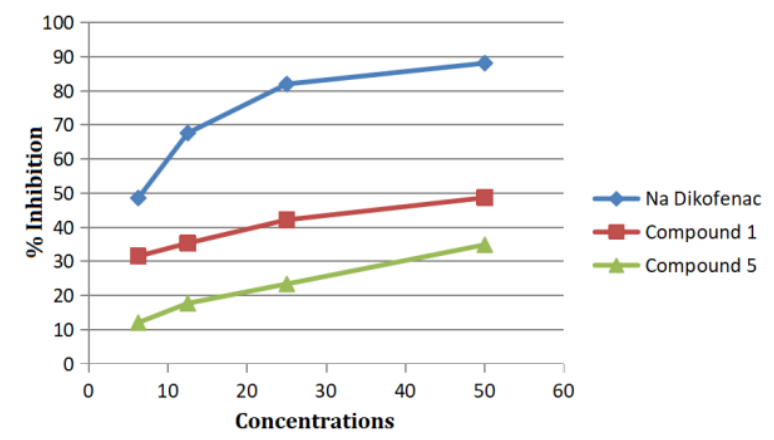

Figure 7. The antidenaturation activity of 1 and 5

\section{CONCLUSION}

Direct amidation of EPMC (1) by using DMF and $\mathrm{NaOH}$ has successful produced $\mathrm{N}, \mathrm{N}$-dimethylp-methoxycinnamamide (5). The reaction was carried out by using the assistance of the irradiation of the unmodified microwaved oven at 300 Watt for $1 \mathrm{~min}$. The product of synthesis was found to still have anti-inflammatory. Structureactivity relationship study suggested that the presence of the $\mathrm{N}, \mathrm{N}$-dimethyl at the nitrogen atom of the $p$-methoxycinnamamide derivative causes a decrease in anti-inflammatory activity. Compound $\mathbf{5}$ that has an amide functional group is more slowly hydrolyzed if compared to $\mathbf{1}$. Hence, it can be concluded that product of synthesis is a more stable compound that still has anti-inflammatory activity.

\section{ACKNOWLEDGMENT}

The researchers would like to thank the Center for Research and Publication, Institution for Research and Community Engagement, Syarif 
Hidayatullah State Islamic University, Indonesia for providing grant research 2016.

\section{REFERENCES}

Buncel E., and Symons E. 1970. The inherent instability of dimethylformamide-water systems containing hydroxide ion. Journal of the Chemical Society D, 1710(0), 164-165.

De Figueiredo RM., Suppo JS., and Campagne JM. 2016. Nonclassical Routes for Amide Bond Formation. Chemical Reviews, 116(19), 12029-12122.

Komala I., Supandi, and Hardiansyah MM. 2018. Direct Amidation of ethyl $p$ methoxycinnamate to Produce N, N -bis- (2hydroxyethyl ) - p -methoxycinnamamide. Jurnal Kimia Valensi, 4(1), 22-25.

Komala I., Supandi, Nurhasni, Betha O., Putri E., et al., 2018. Structure-activity relationship study on the ethyl $\mathrm{p}$-methoxycinnamate as an anti-inflammatory agent. IJC, 18(1),60-65.

Komala, I., Supandi, Nurhasni, Betha, O. S., Yardi, Mufidah, S., Reza, M., Ali, M. S., Aula, N. S., Sutar. 2017. Microwave assisted synthesis of p-methoxycinnamamides and $p$-methoxy- $\beta$ nitrosytrenes from ethyl $p$ methoxycinnamate and screening their antiinflammatory activity. Natural Product Communications, 12(8), 1265-1268.

Pathan RU., and Patil SL. 2008. Synthesis and antimicrobial activity of $\mathrm{N}, \mathrm{N}$-dialkyl cinnamamides. Oriental Journal of
Chemistry, 24(2), 709-712.

Pattabiraman, V. R., \& Bode, J. W. (2011). Rethinking amide bond synthesis. Nature, 480(7378), 471-479.

Sabatini MT., Boulton LT., and Sheppard TD. 2017. Borate esters: Simple catalysts for the sustainable synthesis of complex amides. Science Advances, 3(9), 1-8.

Vrijdag JL., Delgado F., Alonso N., De Borggraeve W. M., Pérez-Macias N., and Alcázar, J. 2014. Practical preparation of challenging amides from non-nucleophilic amines and esters under flow conditions. Chemical Communications, 50 (95), 15094-15097.

Waterman KC., Adami RC., Alsante KM., Antipas A. S., Arenson DR., et al., 2002. Hydrolysis in

Pharmaceutical Formulations. Pharm Dev Tech, 7(2), 113-146.

Williams LAD., O'Connar A., Latore L., Dennis,O., Ringer S., Whittaker JA., et al., 2008. The in vitro anti-denaturation effects induced by natural products and non-steroidal compounds in heat treated (Immunogenic) bovine serum albumin is proposed as a screening assay for the detection of antiinflammatory compounds, without the use of animals. West Indian Medical Journal, 57(4), 327-331 